\title{
The Need for Structural Adjustment: Was It Essential for African Countries over the Decade of the 80's? An Econometric Analysis Using Count Data Models
}

\author{
Samuel Ambapour \\ Institut National de la Statistique, Brazzaville, Republic of Congo \\ Email: ambapour_samuel@yahoo.fr
}

How to cite this paper: Ambapour, S. (2017) The Need for Structural Adjustment: Was It Essential for African Countries over the Decade of the 80 's? An Econometric Analysis Using Count Data Models. Open Journal of Statistics, 7, 599-607. https://doi.org/10.4236/ojs.2017.74041

Received: May 20, 2017

Accepted: August 4, 2017

Published: August 7, 2017

Copyright $\odot 2017$ by author and Scientific Research Publishing Inc. This work is licensed under the Creative Commons Attribution International License (CC BY 4.0).

http://creativecommons.org/licenses/by/4.0/ According to [1], a structural adjustment program gathers a whole of economic (c) (i) Open Access

\section{Keywords}

Structural Adjustment, Count Models, Poisson Model, Negative Binomial Model

\section{Introduction} policy actions aiming to restore macroeconomic balances that enable a country

\begin{abstract}
Several economists agree to say that the need for adjustment was essential for African countries over the decade of the 80's. The econometric analysis of a sample of 28 sub-Saharan African countries, from variables regarded as "representatives" for the adjustment objectives, proves that this assertion cannot be completely rejected.
\end{abstract} to recover sustainable and steady growth over time. In this matter, we can classify the numerous studies undertaken in sub-Saharan Africa in two categories:

- 1) those regarding solely the adjustment need and showing that it results from the conditions in which the growth in 70's was settled [2] [3], on one hand. The factors that hinder the economic growth are generally analyzed carefully and separately between endogenous and exogenous. Actually, those exploratory studies are the ones that showed the "inevitability" of the adjustment, and, according to the words of Mr. M. Marin, Vice-President of European Commission, they enabled "some countries that were close to bankruptcy in early 80's to avoid sinking even more into the darkness of deep recession" (see [3]);

- 2) those that evaluate the impact of adjustment programs on the achieve- 
ments of countries, on the other hand. Many approaches are proposed in general [4]. The analysis before and after structural adjustment, the comparisons between countries which undertook programs for adjustment and those that did not [5] and the analysis based on the modeling of fictitious cases [6] can be distinguished.

In fact, both categories of studies share the same purpose: persuading African countries to undertake some reforms by shaping their macroeconomic policy, to apply for structural adjustment programs in order to balance and relaunch the Economy. The approach adopted in the first case is usually descriptive and based on the evaluation of macroeconomic indicators, which is why it can be qualified as "Economic"; in the second case called "technical", analytical technics a little bit more sophisticated are used. Nevertheless, we can notice in both cases demographic characteristics of involved agents, in terms of age and sex linked to their living conditions are not taking into account [7]. Unfortunately, this text will not be spared from that criticism.

In this article, we consider the first category of studies, while adopting a technical approach at the same time. We want to verify, with a sample of 28 African countries, whether the variables often listed as "representatives" of objectives for structural adjustment are suitable criteria to support the need for adjustment. In other words, is it sufficient to impose an adjustment program to a country just because we notice too high inflation rates for instance? In this purpose, we use a count data model whose adopted specification is Poisson, which specifies the probability of occurrence of an event derived from a count process [8] [9] [10]. The choice for such model can be supported when the studied variable describes the occurrence of an event during a certain period. In our case, "it is the number of times that an African country has been adjusted" during the 1980-1989 period. Furthermore, this model "can also provide a good first approach to describing variables which do not fully meet the conditions of the Poisson model, particularly cases in which the assumption of independence between the present and the past does not hold" [11].

We note this paper and those mentioned above, far from being opposites, are mutually complementary. Its originality or rather its interest lies in the validation's research to the need of adjustment.

The structure of the remainder of this paper is as follows. Section 2 introduces conceptual framework. Section 3 presents the origin of data, as well as the variables used: the endogenous variable which is count variable, and the exogenous variables. Section 4 briefly describes basic functional forms and estimation methods of the most familiar models for count data, Poisson and Negative Binomial models. Section 5 includes the results of econometric estimations. Section 6 discusses our results and the final section provides the conclusions.

\section{Conceptual Framework}

A structural adjustment policy can be defined as a set of provisions resulting 
from negotiation between a country under considerable economic strain and the Bretton Woods institutions. While the International Monetary Fund (IMF) conditions its support through the country's implementation of structural reforms to improve the country's economic functioning, the World Bank, however, assists with loan adjustments by advocating trade liberalization to improve economic competitiveness.

For the structural adjustment program, it can be said it is a set of measures to clean up the economic situation of a country under considerable economic strain. To achieve this, three major objectives are aimed: 1) restoration of a balanced budget; 2) restoration of the trade balance; and 3) the restoration of payments imbalances.

These liberal-oriented adjustment policies have been implemented in many countries since the 1980s and requested on those countries under considerable economic strain to commit themselves to following policy reforms called conditionalities, based on several areas: 1) austerity policy, government's spending cuts; 2) improving governance and fighting corruption; 3) privatization of state-owned enterprises, price liberalization and reduction of public subsidies; 4) improved market functioning; 5) currency devaluation...

\section{Data and Variables Description}

\subsection{Origin of Data}

They derive from a study of [5]. That study aimed, in one hand, to provide elements of comparison for the main macroeconomic variables of Sub-Saharan African countries, English and French speaking countries, members of Franc zone or not, and to highlight the effects of adjustment policies on economic achievements, on the other hand. Twenty-eight countries, for which reliable data covering the period of 1980-1989 were available, was selected. Among the twenty-eight countries, twelve are members of Franc Zone: Benin, Burkina-Faso, Cameroon, Central African Republic, Comoros, Congo, Côte d'Ivoire, Gabon, Mali, Niger, Senegal, Togo. The others countries are: Burundi, Ghana, Kenya, Madagascar, Malawi, Mauritania, Mauritius, Nigeria, Sierra Leone, Somalia, Sudan, Tanzania, The Gambia, Zaire, Zambia, Zimbabwe.

Therefore, for those twenty-eight countries and the considered period, we have data on the following variables: 1) consumer price index; 2) Special Drawing Right (SDR) value of exports and imports; 3) the current balance of payments as a \% of the Gross Domestic Product (GDP); 4) budgetary savings (either definitive revenues excluding donations, minors current expenses including profits) as a \% of revenues; 5) real GDP growth. According to authors named above, these variables were chosen as representatives of objectives for the adjustment: recovering great balances (balance of payments and public finances) and slowing the inflation, while achieving the best growth. However, they can be compared between them regardless of the size of countries and their common currency, because they are either expressed in SDR, or in ratios or in growth 
rate. We also have information about countries that received loans for structural adjustment on the given period: the countries called under adjustment. As we can see, compare to the adopted classification in the introduction, the document of [5] belongs to the second category of studies we qualified as technical. In fact, the purpose was to examine the economic achievements of countries according to the division: the idea of following an adjustment program or not.

\subsection{Variables Description}

\subsubsection{The Endogenous Variable}

The number of times a country have been "under adjustment" during the period of 1980-1989 is the count variable here. A country is considered "under adjustment" in the given year, if one or several agreements have been into force that year (stand-by agreement, extended agreement, agreement under the facility of structural adjustment, agreement under the reinforced facility of structural adjustment) for more than six months overall, and if the country definitely drew more than $50 \%$ of the amounts provided in the agreements for the given year. This definition differs from the one used in certain surveys of the World Bank which usually gives priority to the criterion "signature or renewal of an agreement" (that we can assume as formal agreement) over the effective use of the adjustment policy. For us, the former criterion, with the idea of "drawing at least $50 \%$ of the provided found" reflects an undeniable economic reality. Nevertheless, the actual practice of structural adjustment pointed out that a prime agreement can be followed by new agreements and that non-adjustment periods can occur between the agreements. From our data, we notice 3 countries that had never experience adjustment, 8 countries that adjust but never 3 years in a row, and 17 that adjust at least 3 years in a row.

Based on our count variable, we can say for instance that, Benin has been adjusted once during the considered period, Burkina zero time, Ivory Coast 6 times, and so on.

\subsubsection{The Exogenous Variables}

Among the variables listed before as representatives of the objectives for adjustment, some of them have been used as such. However, others have been combined in order to obtain a more significant ratio. A total of five variables for adjustment need was selected according to the terminology of current use: 1) inflation rate; 2) GDP growth rate; 3) current balance ratio; 4) coverage rate; 5) budgetary savings rate.

However, we know that the exchange policy is relevant to adjustment policies and impacts directly the prices. As an indicator of competitiveness and thus of need for adjustment, the best thing would have been to choose the real effective exchange rate. It is defined as the product of the nominal effective exchange rate against country's consumption price indices with the same price indices oversea. The currency is truly appreciated when this indicator is above 100. Unfortunately, we do not have that data set. But it does not matter because the positive 
effects usually expected from the depreciation of the exchange rate involve promoting the exports, reducing the imports, recovering public finances and more generally, the progressive re-establishment of great economic and financial balances [12]. Yet, all these effects are already taken into account by the selected variables of the need for adjustment. Like it is already said, unlike in the study of [5], measuring the presumed effects of the adjustment in the economic indicators is not our argument, but it is rather the verification of the necessity of the need for adjustment: we adjust because of poor economic achievements. This is why the values of the exogenous variables of the beginning of the period are the ones we considered; those of 1980.

\section{Count Data Models}

\subsection{The Poisson Regression Model}

Poisson model is the basis for the representation and the analysis of count data in the econometric literature. So, we suppose that the endogenous variable, meaning the number of times a country from our sample has been in a situation of adjustment during the study period is drawn from the Poisson distribution. The probability related to the number of times an African country has been in a situation of adjustment is estimated by [13]:

$$
\operatorname{Prob}\left(Y=y_{i} \mid x_{i}\right)=\frac{\exp \left(-\lambda_{i}\right) \lambda_{i}^{y_{i}}}{y_{i} !}=\frac{\exp \left(-\lambda_{i}\right) \lambda_{i}^{y_{i}}}{\Gamma\left(1+y_{i}\right)}, y_{i}=0,1, \cdots, i=1, \cdots, N,
$$

where $\lambda$ is a Poisson parameter such as:

$$
\begin{gathered}
E\left[y_{i} \mid x_{i}\right]=\lambda_{i} \\
\operatorname{Var}\left[y_{i} \mid x_{i}\right]=\lambda_{i}
\end{gathered}
$$

This parameter is linked to $p$ exogenous variables (we assume that there is a constant term in the model) by the Log-linear form:

$$
\lambda_{i}=\exp \left(\alpha+x_{i}^{\prime} \beta\right)
$$

Estimates of the parameters of the model using a sample of $N$ observations are obtained by maximizing the log-likelihood function:

$$
\ln L=\sum_{i=1}^{N}\left[y_{i}\left(\alpha+x_{i}^{\prime} \beta\right)-\lambda_{i}-\ln \Gamma\left(1+y_{i}\right)\right]
$$

The likelihood equations take the characteristically simple form

$$
\partial \ln L / \partial\left(\begin{array}{l}
\alpha \\
\beta
\end{array}\right)=\sum_{i=1}^{N}\left(\begin{array}{c}
1 \\
x_{i}
\end{array}\right)\left(y_{i}-\lambda_{i}\right)=\sum_{i=1}^{N}\left(\begin{array}{c}
1 \\
x_{i}
\end{array}\right) e_{i}=0
$$

\subsection{The Negative Binomial Model}

Some authors consider the "equidispersion" aspect of the model unrealistic. In this reasoning, over-dispersion tests and alternative specifications are proposed [14] [15] [16] [17]. The most frequently cited alternative is the negative binomial regression model or Negbin model [8] [18] [19]. In this modeling, the distribu- 
tion of $y_{i}$ is always Poisson but its mathematical expectation is tainted by an error term $\varepsilon_{i}$. The latter defines diverse errors in the specifications, such as the not consideration of certain explanatory variables independent from $x_{i}$ variables, or else, the unobserved heterogeneity often characterizing individual data. To introduce latent heterogeneity we write [13]:

$$
E\left[y_{i} \mid x_{i}, \varepsilon_{i}\right]=\exp \left(\alpha+x_{i}^{\prime} \beta+\varepsilon_{i}\right)=u_{i} \lambda_{i},
$$

where $u_{i}=\exp \left(\varepsilon_{i}\right)$ is assumed to have a one a gamma distribution $\gamma(\delta, \delta)$, with mean 1 and variance $1 / \delta=k$. So, the conditional Poisson regression is:

$$
\operatorname{Prob}\left[Y=y_{i} \mid x_{i}, \varepsilon_{i}\right]=\frac{\exp \left[-\exp \left(\varepsilon_{i}\right) \lambda_{i}\right]\left[\exp \left(\varepsilon_{i}\right) \lambda_{i}\right]^{y_{i}}}{\Gamma\left(1+y_{i}\right)},
$$

and, the probability density function for the Negative binomial distribution is:

$$
\operatorname{Prob}\left[Y=y_{i} \mid x_{i}\right]=\frac{\Gamma\left(\delta+y_{i}\right) r_{i}^{\delta}\left(1-r_{i}\right)^{y_{i}}}{\Gamma\left(1+y_{i}\right) \Gamma(\delta)}
$$

with $r_{i}=\delta /\left(\delta+\lambda_{i}\right)$

So, the first two moments of Negbin model are:

$$
\begin{gathered}
E\left[y_{i} \mid x_{i}\right]=\lambda_{i} \\
\operatorname{Var}\left[y_{i} \mid x_{i}\right]=\lambda_{i}\left[1+(1 / \delta) \lambda_{i}\right]=\lambda_{i}\left[1+k \lambda_{i}\right]
\end{gathered}
$$

where $k=\operatorname{Var}\left[u_{i}\right]$

The parameters of the Negbin model $(\alpha, \beta, \delta)$ can be estimated by the maximum likelihood. Poisson specification is tested by the null hypothesis $H_{0}: \delta=0$ using the Wald or the likelihood ratio test, or the Lagrange multiplier test.

\section{Estimation Results}

Table 1 presents descriptive statistics for the exogenous variables in the Poisson and Negbin regressions.

The results of econometric estimations for both of these applied models Poisson and Negbin on Limdep software [20] are provided in Table 2. In Poisson model, we notice that three variables out of five are statistically significant at the threshold of 5\% and bear the expected sign; including inflation; GDP growth; and current balance rate. In Negbin model, we can note that the estimated

Table 1. Descriptive summary of statistics for variables of adjustment need.

\begin{tabular}{ccccc}
\hline Variables & Means & Standard deviation & Maximum & Minimum \\
\hline INFLAT & 18.1928 & 0.0076 & 59.0000 & 5.0000 \\
GDP & 3.0000 & 0.0162 & 17.7000 & -10.1000 \\
BALANCE & -8.0000 & 0.0168 & 12.1000 & -21.8000 \\
COVERAGE & 91.1771 & 0.0243 & 305.8000 & 29.1000 \\
BUDGET & -2.5180 & 0.0040 & 64.7000 & -85.5000 \\
\hline
\end{tabular}


Table 2. Regression results for Poisson and Negbin models.

\begin{tabular}{ccccc}
\hline \multirow{2}{*}{ Variables } & \multicolumn{2}{c}{ Poisson } & \multicolumn{2}{c}{ Negbin } \\
\cline { 2 - 5 } & Coeff. & t-stat & Coeff. & t-stat \\
\hline Constant & 0.5563306410 & 1.394 & 0.5404537361 & 1.261 \\
INFLAT & 0.01811721448 & $2.367^{* *}$ & 0.01845728703 & $1.713^{*}$ \\
GDP & -0.04739597910 & $-2.923^{* *}$ & -0.04802365367 & $-2.221^{* *}$ \\
BALANCE & -0.6284326696 & $-3.750^{* *}$ & -0.06338676540 & $-3.238^{* *}$ \\
COVERAGE & 0.001606216725 & 0.660 & 0.001670415958 & 0.522 \\
BUDGET & 0.006183458054 & 1.522 & 0.006195774971 & 1.323 \\
& Log likelihood function $:-60.65069$ & Log likelihood function: -60.63184 \\
\hline
\end{tabular}

$* *,{ }^{*}$ respectively significant at the threshold of $5 \%$ and $10 \%$.

parameters are likely to those obtained from Poisson model. Yet, the inflation rate variable is no more significant at the threshold of $5 \%$, but at $10 \%$. Nevertheless, the likelihood test ratio of both models shows that the constraint relevant to the specification of the Poisson model is accepted.

\section{Discussions}

These results confirm that the higher the inflation rate, the greater the need for adjustment. We note well that a poor GDP growth rate (or negative), leads to a greater number of adjustments. We also notice a negative link between the current balance rate and the number of adjustments. Actually, a country with a highly unprofitable current balance and poor product growth, if not negative, is obviously in need for structural adjustment. It is the same for a country which balances its current account only with the help of a deflationary policy (that is to say with a poor or negative growth): "its need for adjustment is due to a loss of competitiveness and to the fact that it attained its maximum debt level, which makes it harder to balance its current account" [3].

When it comes to the cover rate and the budgetary savings ratio, we notice that the coefficients of both of these variables are not significant and do not bear the sign that is reasonably expected. There are two approaches in statistic. First, we can say that the facts are shown, and that we can just stick to saving them. Second, we can infer that an unreasonable estimation is doubtlessly due to few unwelcome correlations between explicit variables, or due to the omission of a variable, and that it is better to stop the estimation, or, better try to correct it by including some missing variables, or verifying the appropriateness of the set [21]. Yet, if we consider the case of the coverage ratio for instance, the economic theory teaches today that the commercial balance is less and less significant as an indicator, due to high progression of international exchange services that it failed to take into account: insurances, financial services, telecommunications, transports, tourism, brevets, royalties, etc. represent one-third of exchange of goods now [22]. We can imagine a large trade deficit being compensated by a 
surplus of exchange of services then (that we qualify of unnoticeable), or viceversa.

If we exclude the two variables that are not significant, the cover rate and the budgetary savings ratio, the regression from other variables is globally significant. Therefore we can make the statement that the hypothesis about the need for adjustment cannot be totally ignored. This result is reassuring, especially when we focus on what [23] said, "In fact, the growth rate and the balance of payments could synthesize the adjustment need for African countries, members of Franc zone (it also regards other African countries), deriving from the combination of several elements (endless declining terms of trade, capital flight, loose fiscal policy, aggravation of external debt...)". [3] also shares this idea, talking about basic indicators.

\section{Conclusion}

There are several indicators for adjustment need. In this study, we focused on five of them: two basic indicators and three complementary indicators. The results from the econometric count data model tend to confirm the hypothesis of the need for adjustment for African countries included in the analyzed sample, during the 80 's decade. It is obvious that, if we summarize that need by the two basic indicators (the growth rate and the balance of payments), the hypothesis cannot be denied.

\section{Acknowledgements}

The author would like to thank anonymous reviewers for their constructive comments.

\section{References}

[1] Henner, H.F. (1996) Ajustement Structurel et Compétitivité des Economies Africaines, CERDI, Document E.96.34.

[2] World Bank (1994) Adjustment in Africa: Reforms, Results and Road Ahead.

[3] Guillaumont, P. and Guillaumont, S. (1994) Ajustement et Developpement. L'expérience des pays ACP, Afrique, Caraîbe, Pacifique. Economica, Paris.

[4] Thorbecke, E. and Kone, S. (1995) The Impact of Stabilization and Structural Adjustment Programmes on Performance in Sub-Saharan Africa. In: Berthelemy, J.-C., Ed., Whither African Economies? OECD, Paris, 17-56.

[5] Leenhardt, B., L'heriteau, M.F. and Tanke, N. (1991) Une Décennie d'Ajustement en Afrique. Performances comparées de 28 Pays africains, 1980-1989, Notes et Etudes No. 43, CCCE.

[6] Morrison, C., Lafay J.D. and Dessus, S. (1993) La Faisabilité Politique de l'Ajustement dans les Pays Africains. OCDE, Document technique No. 88.

[7] Weekes-Vagliani, W. (1990) Analyse des Variables Socioculturelles et de l'Ajustement en Côte d'Ivoire. OCDE, Document Technique No. 9.

[8] Cameron, A.C. and Trivedi, P.K. (1997) Regression Analysis of Count Data. Cambridge University Press, Cambridge. 
[9] Winkelmann, R. and Zimmermann (1995) Recent Developments in Count Data Modeling and Application. Journal of Economic Surveys, 9, 1-24. https://doi.org/10.1111/j.1467-6419.1995.tb00108.x

[10] Winkelmann, R. (2003) Econometric Analysis of Count Data. Springer Verlag, Heidelberg. https://doi.org/10.1007/978-3-540-24728-9

[11] Gourieroux, C. (2000) Econometrics of Qualitative Dependent Variables. Cambridge University Press, Cambridge. https://doi.org/10.1017/CBO9780511805608

[12] Jaquemot, P. and Assidon, E (1988) Politique de Change et Ajustement en Afrique. Ministère de la Coopération et du Développement, Paris.

[13] Greene, W (2005) Functional Form and Heterogeneity in Models for Count Data. Foundation and Trend in Econometrics, 1, 113-218. https://doi.org/10.1561/0800000008

[14] Hausman, J.A., Hall, B.H. and Griliches, Z. (1984) Econometric Models for Count Data with an Application to the Patents-R and D Relationship. Econometrica, 52, 909-938. https://doi.org/10.2307/1911191

[15] Lee, L.F. (1986) Specification Test for Poisson Regression Models. International Economic Review, 27, 689-706. https://doi.org/10.2307/2526689

[16] Cameron, A.C. and Trivedi, P.K. (1986) Regression Based Tests for Overdispersion in the Poisson Model. Journal of Econometrics, 46, 347-364.

https://doi.org/10.1016/0304-4076(90)90014-K

[17] Mullahy, J. (1986) Specification and Testing of Some Modified Count Data Models. Journal of Econometrics, 33, 341-365. https://doi.org/10.1016/0304-4076(86)90002-3

[18] Lawless, J.F. (1987) Negative Binomial and Mixed Poisson Regressions. The Canadian Journal of Statistics, 15, 209-225. https://doi.org/10.2307/3314912

[19] Hilbe, J.M. (2007) Negative Binomial Regression. Cambridge University Press, Cambridge. https://doi.org/10.1017/CBO9780511811852

[20] Greene, W.H. (2002) LIMDEP, Econometric Modeling Guide. Econometric Software Inc., New York.

[21] Rys, A. and Vaneeclou, N. (1998) Econometrie. Théorie et Application, Nathan.

[22] Clerc, D. (1997) Dictionnaire des Questions Economiques et Sociales. Editions de l'Atelier, Paris.

[23] Gankou, J.M. and Bondoma, Y.D. (1998) Gestion du Taux de Change et Politique d'Ajustement dans les Pays Africains Membres de la Zone Franc. Economica, Paris. 
Submit or recommend next manuscript to SCIRP and we will provide best service for you:

Accepting pre-submission inquiries through Email, Facebook, LinkedIn, Twitter, etc. A wide selection of journals (inclusive of 9 subjects, more than 200 journals)

Providing 24-hour high-quality service

User-friendly online submission system

Fair and swift peer-review system

Efficient typesetting and proofreading procedure

Display of the result of downloads and visits, as well as the number of cited articles Maximum dissemination of your research work

Submit your manuscript at: http://papersubmission.scirp.org/

Or contact ojs@scirp.org 